\title{
Long-term mortality in older patients discharged after acute decompensated heart failure: a prospective cohort study
}

Pierre-André Natella ${ }^{1,2^{*}}$, Philippe Le Corvoisier ${ }^{3,4}$, Elena Paillaud ${ }^{1,5}$, Bertrand Renaud ${ }^{6}$, Isabelle Mahé ${ }^{7,8}$, Jean-François Bergmann ${ }^{7,8}$, Hervé Perchet ${ }^{9}$, Dominique Mottier ${ }^{10,11}$, Olivier Montagne ${ }^{3,4+}$ and Sylvie Bastuji-Garin ${ }^{1,2,12 \dagger}$

\begin{abstract}
Background: Data are available on short- and intermediate-term mortality rates after discharge for acutely decompensated heart failure (ADHF). However, few studies specifically addressed ADHF outcomes in patients aged 75 years or over, who contribute more than half of all ADHF admissions. Our objectives here were to estimate the long-term mortality of patients aged 75 years or over who were discharged after admission for ADHF and to identify factors, especially geriatric findings, independently associated with 2-year mortality.

Methods: This prospective cohort study in five French hospitals included consecutive patients aged 75 years or older and discharged after emergency-department admission for ADHF meeting Framingham criteria $(N=478$; median age, 85 years; 68\% female). Kaplan-Meier 1-year and 2-year survival curves were plotted. Admission characteristics independently associated with overall 2-year mortality were identified using multivariable Cox proportional-hazards regression.

Results: Mortality was 41.7\% (95\% confidence interval [95\% Cl], 37.2\%-53.5\%) after 1 year and 56.0\% (95\% Cl, 51. 5\%-60.7\%) after 2 years. By multivariable analysis, independent predictors of 2-year mortality were male sex (hazard ratio $[H R], 1.36 ; 95 \% \mathrm{Cl}, 1.00-1.82)$, age $>85$ years $(\mathrm{HR}, 1.57 ; 95 \% \mathrm{Cl}, 1.19-2.07)$, higher number of impaired activities of daily living (HR, 1.11 per impaired item; 95\% Cl, 1.05-1.17), recent weight loss (HR, 1.61; 95\% Cl, 1.142.28), and lower systolic blood pressure ( $\mathrm{HR}, 0.86$ per standard deviation increase; $95 \% \mathrm{Cl}, 0.74-0.99)$. Creatinine clearance $\leq 30 \mathrm{~mL} / \mathrm{min}$ showed a trend toward an association with 2-year mortality (HR, 1.36; 95\% Cl, 0.97-2.00).

Conclusion: Functional impairment before admission is associated with higher long-term mortality in patients $\geq 75$ years admitted for ADHF. This study focused on geriatric markers not traditionally collected in heart-failure patients but did not analyse all cardiologic parameters associated with outcomes in other studies. Nevertheless, our findings may contribute to identify those patients admitted for ADHF who have the worst prognosis.
\end{abstract}

Keywords: Acute decompensated heart failure, Long-term mortality, Elderly

\footnotetext{
* Correspondence: pierre.natella@hmn.aphp.fr

${ }^{\dagger}$ Equal contributors

${ }^{1}$ Université Paris Est (UPEC), A-TVB DHU, IMRB, EA7376, CEpiA Clinical

Epidemiology and Ageing unit, Créteil, France

${ }^{2}$ AP-HP, Hôpital Henri Mondor, Service de Santé Publique, Créteil, France

Full list of author information is available at the end of the article
} 


\section{Background}

Heart failure (HF) affects more than 15 million people in Europe, many of whom are elderly [1]. The heavy burden of morbidity and mortality associated with HF is comparable to that of many advanced malignancies [2]. The mean life expectancy of patients discharged after admission for HF has been estimated at 5.5 years [3]. Several studies investigated the short- and intermediateterm risk of death after discharge for acutely decompensated heart failure (ADHF). In patients aged 65 years or more, overall mortality ranged from $25 \%$ to $40 \%$ after 1 year [4-15] and from $22 \%$ to $52.9 \%$ after 2 years [16-18]. However, few studies specifically addressed ADHF outcomes in patients aged 75 years or over $[9,10]$, who contribute more than half of all patients admitted for ADHF [19]. Moreover, only two of these studies reported the associations linking geriatric syndromes to 1-year mortality in elderly patients with $\operatorname{HF}[6,16]$, and none investigated clinical and laboratory variables concomitantly with geriatric findings. These knowledge gaps need to be filled, as the prevalence of chronic diseases increases with age, so that most patients older than 75 years have multiple co-morbidities [20]. We previously reported co-morbidities and functional impairments independently associated with in-hospital mortality of older patients admitted for ADHF (ELISA survey) [21]. Better knowledge of risk factors for long-term mortality may help to define follow-up and management goals and may improve treatment decision-making.

Here, our primary objective was to assess the longterm survival of patients aged 75 years or over and discharged after in-patient treatment of ADHF. We also aimed to identify factors, especially geriatric findings, independently associated with 2-year mortality. To achieve these objectives, we used data from the previously described ELISA cohort study of severe heart failure designed to identify patients with the worst prognosis as early as possible during their hospital stay [21].

\section{Methods}

\section{Study design}

ELISA is a prospective longitudinal cohort study of 680 older patients with ADHF seen at the emergency departments of five French hospitals [21], between October 2004 and December 2007. The ELISA cohort was established in compliance with good clinical practice guidelines and was approved by the appropriate ethics committee (institutional review board of the HenriMondor Teaching Hospital, Créteil, France). Cohort participants or their relatives gave their written informed consent for the collection of personal data to be used in further analyses. The present report complies with the
Strengthening the Reporting of Observational Studies in Epidemiology (STROBE) statement [22].

We estimated 1-year and 2-year mortality rates and we looked for associations linking admission characteristics, including geriatric findings and co-morbidities, to 2-year mortality among hospital survivors.

\section{Patients}

As previously described [21], consecutive patients aged 75 years or older and admitted to an emergency department with a diagnosis of ADHF during a 1-year study period were included in the ELISA cohort if they met Framingham criteria for HF (at least two major criteria or one major criterion plus two minor criteria) [23]; dyspnoea at rest or with minimal exertion; and an expected hospital stay duration $\geq 24 \mathrm{~h}$. Exclusion criteria were ventricular arrhythmia at admission and transfer to another hospital after the initial evaluation. For the present study focusing on survival after hospital discharge, we excluded the patients who died in the hospital.

\section{Data collection}

Included patients underwent a standardised clinical evaluation at the emergency department. However, some parameters such as the get-up-and-go test were collected as early as possible after the relief of ADHF symptoms. Baseline data included socio-demographic characteristics, medical history, clinical characteristics, and laboratory test results. Trained clinical research assistants recorded geriatric parameters using validated tools. Nutritional status was assessed using the Mini Nutritional Assessment-Short Form [24] to classify patients into three nutritional risk categories ( $\geq 12$, well-nourished; $8-11$, at risk; and $<8$, malnourished) [25]. Weight loss over the last three months (none, 1 to $3 \mathrm{~kg}$, or $>3 \mathrm{~kg}$ ) was recorded from the patients or relatives then validated by medical record review. For cognitive status, assessed using the MMSE, the cut-off of 17 indicating severe cognitive impairment was chosen [26-28]. Mood was assessed using the 15-item Geriatric Depression Scale (GDS), with scores $\geq 5$ indicating a risk of depression [29, 30]. Functional status was assessed using the Katz activities of daily living scale (ADL) with six items (bathing, dressing, toileting, transferring, continence, and feeding) scored from 2 (able to perform the activity) to 0 (unable to perform the activity) [31]. The number of impaired ADL items was recorded, as well as the presence of functional impairment defined as a need for assistance for at least one ADL (i.e., ADL score <12). Impaired mobility was defined as a get-up-and-go test time $>20$ s or an inability to perform the test [32]. Glomerular filtration rate was calculated using the abbreviated Modification of Diet in Renal Disease. 
Follow-up after hospital discharge

Patients were monitored by telephone calls at threemonth intervals for 2 years after discharge or until death. Vital status was collected from the next of kin, usual physician, or patient's residential institution. The primary outcome for the present analysis was overall 2-year mortality after discharge.

\section{Statistical analysis}

Sample size was estimated for the main objective of the ELISA cohort, namely, the identification of factors associated with in-hospital mortality [21].

All tests were two-sided, and $P$ values $\leq 0.05$ were considered significant. Analyses were performed using STATA software version 12.0 (StataCorp, College Station, TX, USA). No imputation for missing data was performed.

Quantitative data are described as mean \pm SD or median $\left[25^{\text {th }}-75^{\text {th }}\right.$ centiles], as appropriate, and categorical variables as $\mathrm{n}$ (\%). Overall survival was assessed from discharge to death from any cause, 2 years after hospital discharge or last follow-up for censored patients. We used the non-parametric Kaplan-Meier method to estimate 1-year and 2-year survival rates with their 95\% confidence intervals (95\% CIs).

Characteristics of survivors and non-survivors were compared using Cox proportional hazards regression models with estimation of hazard ratios (HRs) and their 95\% CIs. Log-linearity was tested for quantitative variables. Analyses were routinely adjusted for age dichotomised based on the median value ( $>85$ versus $\leq 85$ years). Variables associated with $P$ values $<0.15$ were selected for multivariable analyses. Confounders and interactions were tested in bivariate models. We also investigated a potential centre effect. To avoid introducing correlated variables into multivariable models, correlations were assessed using Cramer's V for categorical variables [33] and Spearman's non-parametric rank correlation (Rho) [34] for quantitative variables; values above 0.50 were considered to indicate correlations. The most relevant variables were identified based on clinical relevance, number of missing values, and the Akaike information criterion (AIC) $[35,36]$. The proportional hazards assumption was assessed both graphically and statistically using the Schoenfeld residuals test. This assumption was met for all variables in the final models. Calibration and discrimination of the final multivariable model were assessed using the Gronnesby-Borgan goodness-of-fit test and Harrell's cindex, respectively [37, 38]. Model robustness was tested using a non-parametric bootstrap resampling procedure. The final Cox model was refit for the 500 bootstrap samples thus created [39].

\section{Results}

Among the 680 patients initially assessed for eligibility, 478 were analysed (Fig. 1). Table 1 reports their baseline characteristics. Median age was 85 years (range, 75-105 years). Most patients (91\%) had one or more cardiovascular co-morbidities (myocardial infarction, stroke, hypertension, and/or arrhythmia). More than half of patients had abnormal nutritional status, function, and/or mobility. Polypharmacy was the rule (median, 7 drugs).

The $36(7.5 \%)$ patients lost to follow-up were censored at the date of last information. Median follow-up was 14.1 months (449 days [132-718 days]; range, 1770 days). Mortality was $41.7 \%$ (95\% CI, 37.2\%-53.5\%) after 1 year and 56.0\% (95\% CI, 51.5\%-60.7\%) after 2 years (Fig. 2). Median overall survival was 19 months (1.6 years). Most deaths occurred early after hospital discharge, after a median of about 6 months (184 days [68-367 days]).

\section{Factors associated with 2-year survival}

By univariate analysis (Table 2), factors significantly associated with mortality were older age (Fig. 3); male sex; anaemia; lower systolic blood pressure; renal failure; lower body mass index, malnutrition, and recent weight loss; and impairments in functional status and mobility. Trends $(P<0.15)$ were observed for history of myocardial infarction and severe cognitive impairment. Therefore, these variables were potential candidates for multivariable analysis. Neither other cardiovascular co-morbidities nor polypharmacy were associated with 2-year mortality. No centre effect or effect modification by centre was demonstrated.

Age, sex, creatinine clearance, anaemia, systolic blood pressure, myocardial infarction, weight loss, body mass index, MNA-SF score, ADL score, Timed Get-Up-and-

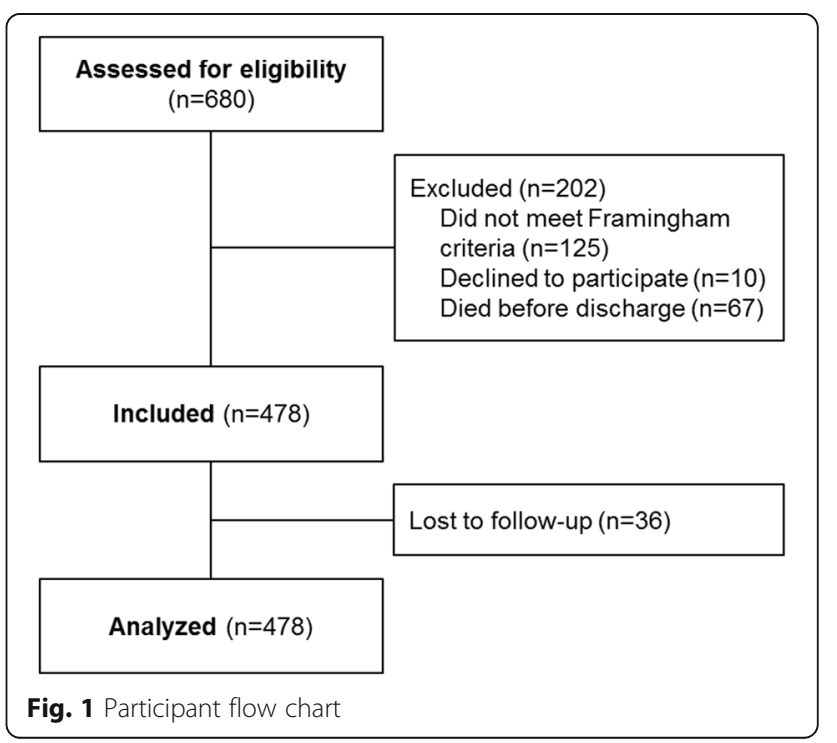


Table 1 Baseline characteristics of elderly patients admitted for acute decompensated heart failure

\begin{tabular}{ll}
\hline Characteristics & Total \\
& $n=478$ \\
\hline
\end{tabular}

Socio-demographic characteristics

Age $>85$ years

$222(46)$

Male sex

$155(32.4)$

Living arrangements $(n=220 / 244)$

Lives alone

$386(83.2)$

Institutionalised

(16.8)

Current or former smoker $(n=211 / 242)$

$110(24.3)$

Medical status

Co-morbidities (past or current):

Arteritis $(n=207 / 234)$

$53(12.0)$

Myocardial infarction $(n=220 / 251)$

Stroke $(n=218 / 245)$

Anaemia $(n=209 / 233)$

Hypertension $^{\mathrm{a}}(n=223 / 254)$

Cardiac arrhythmia $(n=215 / 245)$

Diabetes $(n=218 / 253)$

Systolic blood pressure, $\mathrm{mmHg}(n=210 / 249)$

Number of drugs

$\geq 5$ drugs per day

Minnesota Living with Heart Failure

Questionnaire $(n=100 / 102)$

$<24$ (good quality of life)

54 (26.7)

[24-45] (intermediate quality of life)

$>45$ (poor quality of life)

97 (48.0)

$51(25.2)$

Laboratory parameters at admission

Sodium, $\mathrm{mmol} / \mathrm{L}(n=282 / 188)$

Haemoglobin, g/dL $(n=212 / 247)$

Creatinine clearance, $\mathrm{mL} /$ minute $^{\mathrm{b}}(n=218 / 250)$

$\geq 60$

]30-60[

$\leq 30$

Nutritional parameters

Body mass index, $\mathrm{Kg} / \mathrm{m}^{2}(n=146 / 166)$

$<19$

$10(3.2)$

[19-21 [

$18(5.8)$

[21-23 [

39 (12.5)

$\geq 23$

$245(78.5)$

MNA-SF score $(n=69 / 81)$

$\geq 12$ (well-nourished)

$58(38.7)$

[8-12] (at risk)

$73(48.7)$

$<$ (malnourished)

$19(12.7)$

Recent weight loss $>3 \mathrm{Kg}$ ( $<3$ months) $(n=201 / 226)$
Table 1 Baseline characteristics of elderly patients admitted for acute decompensated heart failure (Continued)

$\begin{array}{ll}\begin{array}{l}\text { Non-solid nutrition (blended or minced) } \\ (n=215 / 238)\end{array} & 82(18.1) \\ \text { Function and mobility } & \\ \text { Number of impaired ADL items }(n=201 / 226) & 2[0-5] \\ \text { ADL score }<12,(n=201 / 226) & 268(62.8) \\ \text { Timed get-up-and-go }>20 \mathrm{~s}^{\mathrm{c}},(n=178 / 210) & 296(76.2) \\ \text { Cognition } & \\ \text { MMSE } \leq 17, \text { severe impairment }(n=221 / 251) & 97(20.6)\end{array}$

Depression

GDS score $\geq 5(n=143 / 148)$

$142(48.8)$

Quantitative variables are expressed as median [25th - 75th centiles] and categorical variables as $\mathrm{N}(\%)$

$(n=\Lambda)$ indicates the number of patients in each group in case of missing data MNA-SF, Mini Nutritional Assessment-Short Form; ADL, activities of daily living scale; MMSE, Mini Mental State Examination; GDS, Geriatric Depression Scale ${ }^{a}$ Hypertension was defined as blood pressure $\geq 140 / 90 \mathrm{mmHg}$ or treatment for hypertension

${ }^{\mathrm{b}}$ Creatinine clearance was calculated using the abbreviated Modification of Diet in Renal Disease formula, glomerular filtration rate $\left(\mathrm{mL} / \mathrm{min} / 1.73 \mathrm{~m}^{2}\right)=$ $186.3 \times$ [creatinine $(\mu \mathrm{mol} / \mathrm{L}) / 88.4]^{-1.154} \times[\text { Age (years) }]^{-0.203} \times 0.742$ (if female) $\times$ 1.21 (if black)

'Timed Get-Up-and-Go test $>20 \mathrm{~s}$ or patient unable to perform the test

Go score, and MMSE score were available for the multivariable Cox model. Mobility impairment, lower body mass index, and MNA-SF category were not introduced into multivariable models, as they correlated with functional impairment and recent weight loss, respectively (correlation index $>0.5, P<0.05$ ). Because of their association with other parameters, anaemia, myocardial infarction, and cognitive impairment were not independently associated with death in the multivariable model $(P>0.15)$. No significant interactions were found between variables associated with 2-year mortality. By multivariable analysis (Table 3), five factors were independently associated with 2-year mortality, namely, male sex, age older than 85 years, higher number of impaired ADL items, recent weight loss, and lower systolic blood pressure. A trend was noted for renal failure. The final model had good calibration $(P$ value of the goodness-of-fit test $>0.20$ ) and acceptable discrimination (Harrell's c-index, 0.64). The HRs estimated after bootstrap resampling were close to those of the original model, suggesting excellent internal validity. All five factors were also independently associated with 1-year mortality (Additional file 1: Table S1).

\section{Discussion}

High 1-year and 2-year mortality rates of $41.7 \%$ and $56.0 \%$, respectively, were documented in unselected elderly patients discharged alive after treatment for ADHF. Independent risk factors for death within 2 years were older age, male sex, prior functional impairment, low 


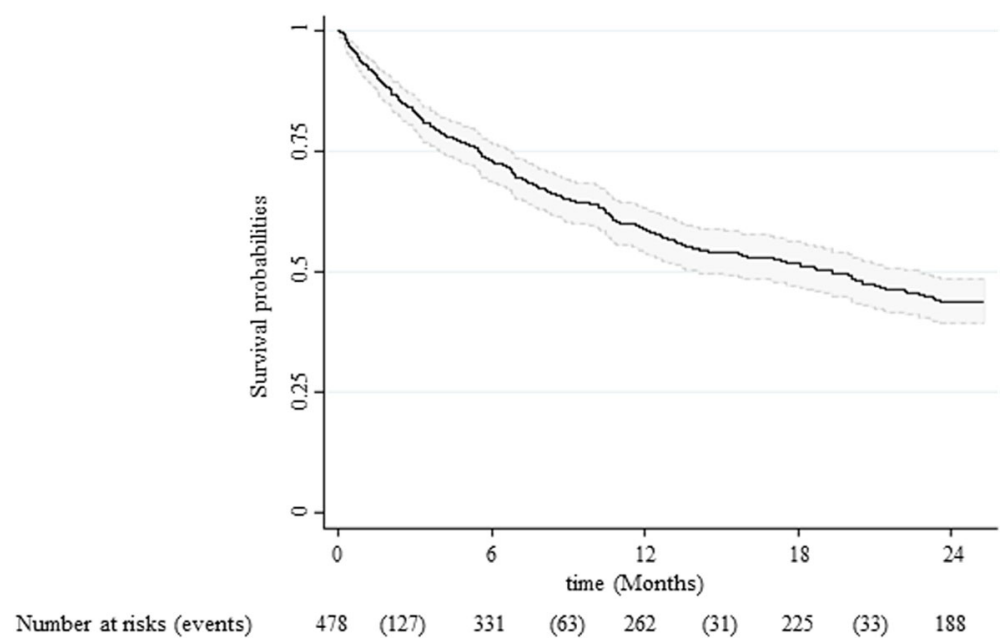

Fig. 2 Kaplan-Meier survival distribution, with 95\% confidence intervals, of 478 patients aged 75 years or over and discharged after admission for acutely decompensated heart failure

systolic blood pressure at admission, and recent weight loss. A trend was observed for renal failure.

One-year mortality rates close to $40 \%$ have been reported in subgroups of elderly patients in Canada, the United States, and Israel [5, 7, 10, 11, 14], in keeping with the $41.7 \%$ rate in our ELISA cohort. Other studies obtained variable results. In a Scottish study, 1-year mortality rates were $49 \%$ and $56 \%$ in the groups aged 75-84 years and $>84$ years, respectively [4]. In contrast, several studies from Spain, Canada, the United States, and Europe (EHFS II survey) found 1-year mortality rates of about $30 \%[6,8,9,13]$. These discrepancies may reflect differences in inclusion criteria regarding age, ADHF versus newly diagnosed $\mathrm{HF}$, and presentation to the emergency department versus elsewhere. The 2-year mortality rate of $56 \%$ in our study is consistent with previous reports from Brazil and the United States [17, 18]. Conversely, an Italian study [16] estimated 2-year mortality at $22.9 \%$. This difference may be ascribable to the younger mean age of 74 years and lesser severity of HF (NYHA class II).

We identified several admission characteristics that predicted 2-year mortality in elderly patients admitted for ADHF. The discrimination level of our final multivariable model (Harrell's c-index, 0.64) suggests an influence on long-term mortality of additional variables not evaluated in our study. Indeed, other factors previously associated with increased mortality in patients with $\mathrm{HF}$, e.g., type and duration of HF or medical therapy, may also have affected patient outcomes in our study. Three of the six parameters independently associated with 1year and 2-year mortality, namely, lower systolic blood pressure, renal failure, and functional impairment before admission, were also associated with in-hospital mortality in the ELISA cohort [21].

Several studies previously documented an independent adverse effect of male sex and older age on mortality in elderly patients with HF, in keeping with our results [4, $5,7,8,11,16]$. Similarly, lower systolic blood pressure [9-11, 13, 16-18] and renal dysfunction [9-11] were also previously associated with mortality.

Few studies have assessed pre-admission functional impairment as a prognostic marker in elderly patients with ADHF. The association of this factor with 2-year mortality in our population is consistent with two studies assessing associations between findings from a global geriatric assessment and 1-year mortality [6, 12]. These two studies and ours produced similar results despite using different functional assessment tools (Katz ADL, Barthel index, or instrumental ADL), a fact that supports the validity of our results. That neither of the two previous studies found associations of mortality with other factors, including older age, male sex, systolic blood pressure, and renal impairment, may be ascribable to limited statistical power (88 and 162 patients). Furthermore, in the octogenarians of the EHFS II survey, disability ('self-care problems') independently predicted long-term mortality in the multivariable analysis [9]. Our results are consistent with those of studies in other clinical settings, in which functional status predicted mortality independently from the underlying medical conditions. Interestingly, the 2-year risk of death in our population increased by $11 \%$ for each additional impaired ADL item.

Another important finding from our study is the influence of nutritional status. Not only recent weight loss, 
Table 2 Comparison of survivors and non-survivors using age-adjusted Cox proportional hazards regression models

\begin{tabular}{|c|c|c|c|c|}
\hline \multirow[t]{2}{*}{ Characteristics } & \multirow{2}{*}{$\begin{array}{l}\text { Survivors } \\
n=224\end{array}$} & \multirow{2}{*}{$\begin{array}{l}\text { Non-survivors } \\
n=254\end{array}$} & \multirow{2}{*}{$\begin{array}{l}\text { Age-adjusted analysis }{ }^{a} \\
\text { HR }[95 \% \mathrm{Cl}]\end{array}$} & \multirow[t]{2}{*}{$P$ value } \\
\hline & & & & \\
\hline \multicolumn{5}{|l|}{ Socio-demographic characteristics } \\
\hline Age $>85$ years & $88(39.0)$ & $134(53)$ & $1.49[1.17-1.91]$ & 0.01 \\
\hline Male sex & $63(28.1)$ & $92(36.2)$ & $1.32[1.02-1.72]$ & 0.03 \\
\hline \multicolumn{5}{|l|}{ Living arrangements $(n=220 / 244)$} \\
\hline Lives alone & $188(85.5)$ & $198(81.1)$ & 1 & \\
\hline Institutionalised & $32(14.5)$ & $46(18.9)$ & $1.17[0.84-1.61]$ & 0.35 \\
\hline Current or former smoker $(n=211 / 242)$ & $53(25.1)$ & $57(23.6)$ & $1.00[0.74-1.34]$ & 0.99 \\
\hline \multicolumn{5}{|l|}{ Medical status } \\
\hline \multicolumn{5}{|l|}{ Co-morbidities (past or current): } \\
\hline Arteritis ( $n=207 / 234)$ & $19(9.2)$ & $34(14.5)$ & $1.28[0.89-1.85]$ & 0.18 \\
\hline Myocardial infarction $(n=220 / 251)$ & $36(16.4)$ & $61(24.3)$ & $1.27[0.95-1.69]$ & 0.11 \\
\hline Stroke $(n=218 / 245)$ & $20(9.2)$ & $31(12.7)$ & $1.29[0.86-1.83]$ & 0.24 \\
\hline Anaemia $(n=209 / 233)$ & $44(21.1)$ & $72(30.9)$ & $1.34[1.02-1.77]$ & 0.04 \\
\hline Hypertension $^{\mathrm{b}}(n=223 / 254)$ & $166(74.4)$ & $188(74.0)$ & $0.96[0.72-1.27]$ & 0.76 \\
\hline Cardiac arrhythmia $(n=215 / 245)$ & $141(65.6)$ & $172(70.2)$ & $1.02[0.77-1.35]$ & 0.87 \\
\hline Diabetes $(n=218 / 253)$ & $43(19.7)$ & $41(16.2)$ & $0.93[0.66-1.31]$ & 0.70 \\
\hline Systolic blood pressure, $\mathrm{mmHg}(n=210 / 249)^{c}$ & 150 [135-170] & $141[121-162]$ & $0.83[0.73-0.96]$ & 0.01 \\
\hline Number of drugs & $7[5-9]$ & $7[5-9]$ & & \\
\hline$\geq 5$ drugs per day & $171(76.3)$ & $211(83.1)$ & $1.26[0.91-1.75]$ & 0.17 \\
\hline \multicolumn{5}{|c|}{ Minnesota Living with Heart Failure Questionnaire $(n=100 / 102)$} \\
\hline$<24$ (good quality of life) & $29(29.0)$ & $25(24.5)$ & 1 & 0.69 \\
\hline [24-45] (intermediate quality of life) & $46(46.0)$ & $51(50.0)$ & $1.16[0.72-1.88]$ & \\
\hline$>45$ (poor quality of life) & $25(25.0)$ & $26(25.5)$ & $1.27[0.73-2.21]$ & \\
\hline \multicolumn{5}{|l|}{ Laboratory parameters at admission } \\
\hline Sodium, $\mathrm{mmol} / \mathrm{L}(n=282 / 188)$ & 138 [135-141] & 138 [135-141] & $0.99[0.97-1.01]$ & 0.43 \\
\hline Haemoglobin, g/dL ( $n=212 / 247)$ & $12.5[11.3-13.7]$ & $12.1[10.9-13.4]$ & $0.97[0.92-1.04]$ & 0.40 \\
\hline \multicolumn{5}{|l|}{ Creatinine clearance, $\mathrm{mL} /$ minute $^{\mathrm{d}}(n=218 / 250)$} \\
\hline$\geq 60$ & $117(53.7)$ & $96(38.4)$ & 1 & \\
\hline$[30-60]$ & $83(38.1)$ & $113(45.2)$ & $1.28[0.97-1.68]$ & 0.08 \\
\hline$\leq 30$ & $18(8.3)$ & $41(16.4)$ & $1.81[1.25-2.61]$ & $<0.01$ \\
\hline \multicolumn{5}{|l|}{ Nutritional parameters } \\
\hline \multicolumn{5}{|l|}{ Body mass index, $\mathrm{Kg} / \mathrm{m}^{2}(n=146 / 166)$} \\
\hline$<19$ & $2(1.4$ & $8(4.8)$ & $2.30[1.11-4.74]$ & 0.03 \\
\hline$[19-21[$ & $5(3.4)$ & $13(7.8)$ & $1.50[0.84-2.67]$ & 0.19 \\
\hline$[21-23[$ & $14(9.6)$ & $25(15.1)$ & $1.50[0.98-2.31]$ & 0.08 \\
\hline$\geq 23$ & $125(85.6)$ & $120(72.3)$ & 1 & \\
\hline \multicolumn{5}{|l|}{ MNA-SF score $(n=69 / 81)$} \\
\hline$\geq 12$ (well-nourished) & $33(47.8)$ & $25(30.9)$ & 1 & \\
\hline [8-12[(at risk) & $31(44.9)$ & $42(51.9)$ & $1.64[0.99-2.70]$ & 0.05 \\
\hline$<8$ (malnourished) & $5(7.2)$ & $14(17.3)$ & $3.01[1.52-5.97]$ & $<0.01$ \\
\hline Recent weight loss $>3 \mathrm{Kg}$ (<3 months) $(n=201 / 226)$ & $22(10.9)$ & $42(18.6)$ & $1.59[1.22-2.06]$ & $<0.01$ \\
\hline Non-solid nutrition (blended or minced) $(n=215 / 238)$ & $31(14.4)$ & $51(21.4)$ & $1.60[0.94-1.76]$ & 0.11 \\
\hline
\end{tabular}


Table 2 Comparison of survivors and non-survivors using age-adjusted Cox proportional hazards regression models (Continued)

\begin{tabular}{|c|c|c|c|}
\hline \multicolumn{4}{|l|}{ Function and mobility } \\
\hline Number of impaired ADL items $(n=201 / 226)^{\mathrm{e}}$ & $1[0-4]$ & $2[0-5]$ & $1.10[1.05-1.17]$ \\
\hline ADL score $<12$, $(n=201 / 226)$ & $106(52.7)$ & $162(71.7)$ & 1.61 [1.20-2.16] \\
\hline Timed get-up-and-go $>20 s^{f},(n=178 / 210)$ & $125(70.2)$ & $171(81.4)$ & $1.49[1.05-2.11]$ \\
\hline \multicolumn{4}{|l|}{ Cognition } \\
\hline MMSE $\leq 17$, severe impairment $(n=221 / 251)$ & $38(17.2)$ & $59(23.5)$ & $1.26[0.94-1.69]$ \\
\hline \multicolumn{4}{|l|}{ Depression } \\
\hline GDS score $\leq 5(n=143 / 148)$ & $71(49.7)$ & $71(48.0)$ & $0.96[0.70-1.33]$ \\
\hline \multicolumn{4}{|c|}{ 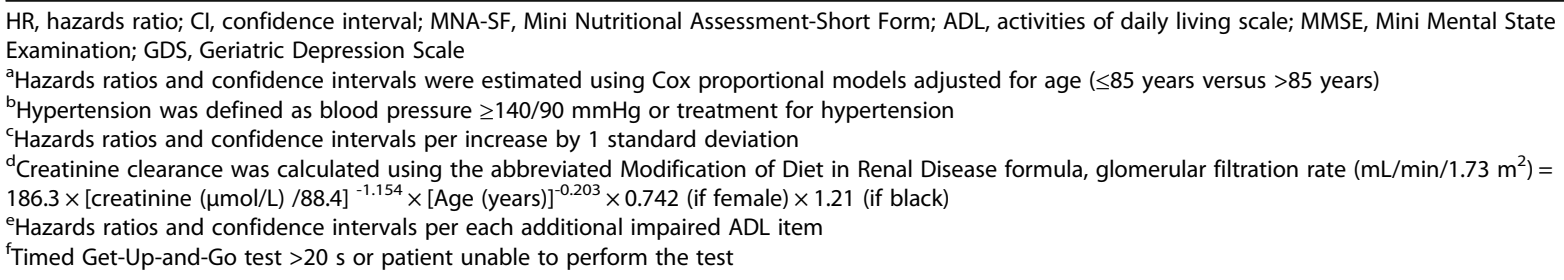 } \\
\hline
\end{tabular}

but also malnutrition or risk of malnutrition, predicted mortality independently from age. The only previous study assessing the prognostic value of MNA results in elderly patients with HF found no association with mortality [6]. However, in older adults, malnutrition is often related to adverse health outcomes and strongly predicts mortality [40, 41]. Weight loss is common in end-stage HF and may reflect numerous mechanisms including neurohormonal dysregulation and an imbalance between anabolism and catabolism [42]. Our results show that recent weight loss is a major prognostic marker in elderly patients successfully treated for an episode of ADHF.

Two of the six factors independently associated with mortality are recognized indicators of fragility. Thus,

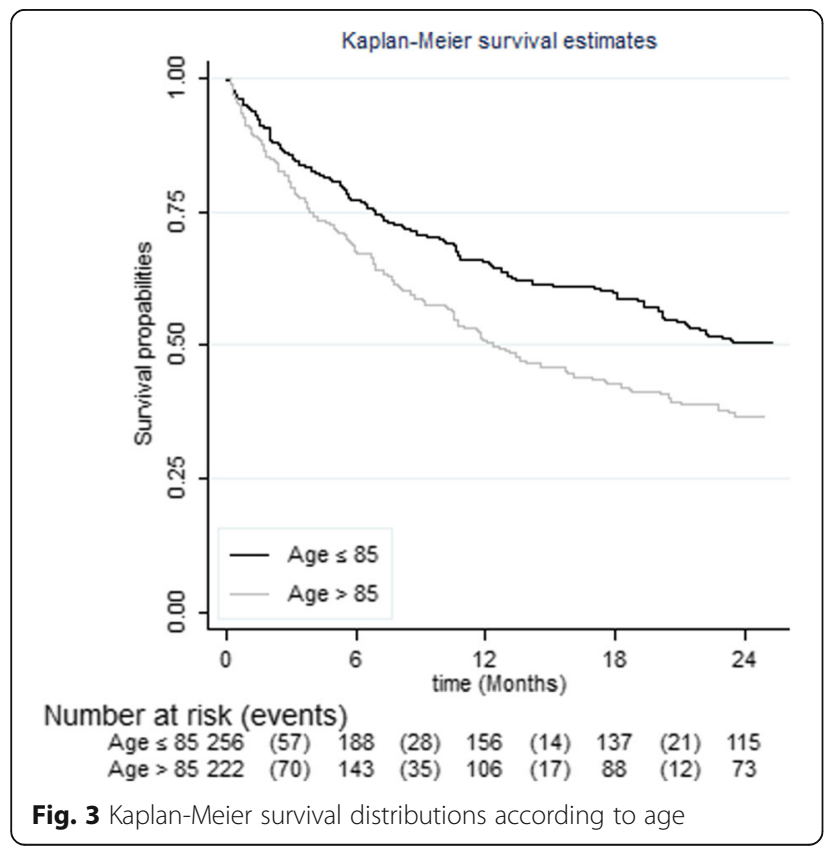

recent weight loss is part of the Fried phenotype, and functional impairment is related to the slowness and low physical activity criteria [43]. Furthermore, impairment of one ADL item corresponds to the 6th and 7th categories of the Canadian Study of Health and Aging frailty scale [44]. Frailty assessed using both a frailty index and the Fried phenotype predicted mortality among community-dwelling patients with HF (mean age, 71 years) [45]. These results suggest that elderly patients with HF may require a specific functional and nutritional evaluation to allow the development of a customised treatment plan aimed at improving outcomes. A number of measures might prove useful. For example, studies in chronic HF showed that exercise training produced statistically significant improvements in selfreported health status among both younger adults [46] and elderly individuals [47], although mortality was not significantly affected. Furthermore, the programmes for elderly patients focused mainly on aerobic and resistance training and did not include a routine assessment of nutritional and functional status [47]. The cost-effectiveness of a multidisciplinary disease management programme has been evaluated in elderly outpatients with HF and mild-to-moderate frailty [48]. Interventional studies might be useful to assess whether similar programmes decrease mortality and/or improve function and quality of life of elderly patients discharged after an ADHF episode.

In a previous study, cognitive impairment was associated with higher long-term mortality in elderly patients with chronic HF, but no multivariable analysis was reported [49]. In our cohort, a crude association was observed, but only a trend towards an association persisted in the age-adjusted analysis and there was no significant association by multivariable analysis. Other prognostic factors in elderly patients with ADHF have been reported [4, 5, 7, 9-11, 17]. 
Table 3 Factors independently associated with 2-year mortality by multivariable analysis $(n=399)$

\begin{tabular}{|c|c|c|c|c|}
\hline \multirow[t]{2}{*}{ Characteristics } & \multicolumn{2}{|c|}{ Model development ${ }^{a}$} & \multicolumn{2}{|c|}{ Parameter estimates after bootstrapping methods } \\
\hline & $\mathrm{HR} 95 \% \mathrm{Cl}$ & $P$ value & Mean $\mathrm{HR} 95 \% \mathrm{Cl}$ & $P$ value \\
\hline Male sex & $1.36[1.00-1.82]$ & 0.05 & $1.36[1.00-1.83]$ & 0.05 \\
\hline Age $>85$ years & $1.57[1.19-2.07]$ & $<0.01$ & $1.58[1.19-2.08]$ & $<0.01$ \\
\hline Number of impaired $A D L^{b}$ items & $1.11[1.05-1.17]$ & $<0.01$ & $1.11[1.04-1.18]$ & $<0.01$ \\
\hline Recent weight loss ${ }^{c}$ & $1.61[1.14-2.28]$ & $<0.01$ & $1.61[1.12-2.32]$ & 0.01 \\
\hline Systolic blood pressure $(\mathrm{mmHg})^{d}$ & $0.86[0.74-0.99]$ & 0.04 & $0.85[0.73-1.00]$ & 0.05 \\
\hline 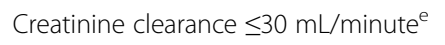 & $1.36[0.97-2.00]$ & 0.09 & $1.38[0.89-2.08]$ & 0.12 \\
\hline
\end{tabular}

$\mathrm{HR}$, hazards ratio; $\mathrm{Cl}$, confidence interval; $\mathrm{ADL}$, activities of daily living scale

${ }^{a}$ Hazards ratios and confidence intervals were estimated using Cox proportional models simultaneously adjusted for all variables listed in the table ber additional impaired ADL item

c $>3 \mathrm{Kg}$ within the 3 months preceding admission

dper increase by 1 standard deviation

${ }^{\mathrm{e} C r e a t i n i n e ~ c l e a r a n c e}$ was calculated using the abbreviated Modification of Diet in Renal Disease formula, glomerular filtration rate $\left(\mathrm{mL} / \mathrm{min} / 1.73 \mathrm{~m}{ }^{2}\right)=$

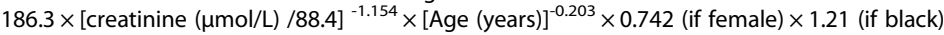

We found no significant associations with long-term mortality for other factors, such as diabetes, myocardial infarction, stroke, and hyponatremia. These results may be related to the inclusion of functional impairment in our multivariable model and to differences in inclusion criteria across studies.

\section{Strength and limitations}

The inclusion in a vast multicentre cohort of unselected elderly patients with successful in-hospital treatment for ADHF and the low lost-to-follow-up rate over 2 years $(7.5 \%)$ support the validity of our results. Furthermore, the inclusion of consecutive patients limited the risk of selection bias, and the main endpoint (overall mortality) is a robust criterion that leaves little room for classification bias. Finally, we routinely adjusted all analyses for age as a potential confounder, and we took interactions and confounding into account in the analyses. The similar HR values obtained after bootstrapping resampling procedures further support the robustness of our findings. Moreover, few data exist on long-term outcomes of patients older than 75 years after successful inhospital ADHF management. A limitation of our study is the absence in the analysis of several factors having previously reported associations with increased mortality, such as, ventricular function, BNP or NT-proBNP concentration, and treatments. Several studies suggest that a score including NT-proBNP may predict post-discharge 1 -year mortality in ADHF populations with a mean age of about 60-75 years; therefore, in our population of very elderly patients, using this score to adjust the fragility indicators associated with post-discharge mortality would have been of interest [15]. However, our findings demonstrate the prognostic value of geriatric characteristics in elderly patients with ADHF.

\section{Conclusion}

Independent predictors of 2-year mortality in unselected elderly patients discharged after inhospital treatment for ADHF included not only older age, male sex, lower systolic blood pressure, and lower creatinine clearance; but also geriatric markers of frailty, such as functional impairment and recent weight loss. An assessment of frailty should therefore be considered an integral part of the evaluation of elderly patients admitted for ADHF. For this frail population, an interdisciplinary approach targeting the multidimensional aspects of health may improve outcomes.

\section{Additional file}

Additional file 1: Table S1. Factors independently associated with 1 -year mortality by multivariable analysis $(n=399)$. (DOC $40 \mathrm{~kb}$ )

\section{Abbreviations \\ ADHF: Acutely Decompensated Heart Failure; ADL: Activities of Daily Living scale; AIC: Akaike Information Criterion; BNP: Brain Natriuretic Peptide; Cl: Confidence Interval; GDS: Geriatric Depression Scale; HF: Heart Failure; HR: Hazard Ratio; MMSE: Mini Mental State Examination; MNA-SF: Mini Nutritional Assessment-Short Form; NT-proBNP: N-Terminal pro-Brain Natri- uretic Peptide; NYHA: New York Heart Association classification; SD: Standard Deviation; STROBE: Strengthening the Reporting of Observational Studies in Epidemiology}

\section{Acknowledgements}

We thank Katia Le Dudal for technical support and A Wolfe, MD, for editing the manuscript

\section{Funding}

This work was supported by a grant from the Hospital Clinical Research Program of the French Ministry of Health (PHRC AOM 02-109). The funders had no role in study design, data collection and analysis, decision to publish, or preparation of the manuscript.

Availability of data and materials

Assistance Publique-Hôpitaux de Paris (AP-HP) owns the data, of which any use or transmission to a third party cannot be made without its prior agreement. 


\section{Authors' contributions}

Individual contribution of each author: Study conception and design: $\mathrm{OM}$ BR, and PLC. Acquisition of data: BR, IM, JFB, HP, DM, and OM. Analysis and interpretation of data: PAN, SBG, PLC, OM and EP. Statistical expertise: SBG. Drafting the manuscript: PAN, SBG, PLC, EP and OM. Critical revision of the manuscript: all authors. All authors read and approved the final manuscript.

\section{Competing interests}

The authors declare that they have no competing interests.

\section{Consent for publication}

Not applicable as our manuscript does not contain data from any individual person.

\section{Ethics approval and consent to participate}

The ELISA cohort was established in compliance with good clinical practice guidelines and was approved by the appropriate ethics committee (institutional review board of the Henri-Mondor Teaching Hospital, Créteil, France). Cohort participants or their relatives gave their written informed consent for the collection of personal data to be used in further analyses.

\section{Author details}

'Université Paris Est (UPEC), A-TVB DHU, IMRB, EA7376, CEpiA Clinical Epidemiology and Ageing unit, Créteil, France. ${ }^{2}$ AP-HP, Hôpital Henri Mondor, Service de Santé Publique, Créteil, France. ${ }^{3}$ Inserm, Centre d'Investigation Clinique, 1430 Créteil, France. ${ }^{4}$ AP-HP, Hôpital Henri Mondor Pôle Vigilance Recherche Méthodologie \& Information Médicale, 94010 Créteil, France. ${ }^{5} \mathrm{AP}-\mathrm{HP}$, Hôpital Henri Mondor, Département de Médecine Interne et Gériatrie, Créteil, France. ${ }^{6}$ AP-HP, Hôpital Henri Mondor, Structure des Urgences, Créteil, France. ${ }^{7}$ AP-HP, Hôpital Lariboisière-Fernand Widal, Département de Médecine Interne, Paris, France. ${ }^{8}$ Université Paris 7, EA REMES Université Paris Diderot, Sorbonne Paris Cité, Paris, France. ${ }^{9}$ Centre hospitalier de Meaux, Service de Cardiologie, Meaux, France. ${ }^{10} \mathrm{CHU}$ Brest, Hôpital Cavale Blanche, Département de Médecine Interne et de Pneumologie, Brest, France. ${ }^{11}$ Université de Bretagne Occidentale, EA 3878 (GETBO), Brest, France. ${ }^{12}$ AP-HP, Hôpital Henri Mondor, Unité de Recherche Clinique, Créteil, France.

Received: 18 June 2016 Accepted: 13 January 2017

Published online: 26 January 2017

\section{References}

1. McMurray JJV, Adamopoulos S, Anker SD, Auricchio A, Böhm M, Dickstein K, et al. ESC guidelines for the diagnosis and treatment of acute and chronic heart failure 2012: The Task Force for the Diagnosis and Treatment of Acute and Chronic Heart Failure 2012 of the European Society of Cardiology. Developed in collaboration with the Heart Failure Association (HFA) of the ESC. Eur J Heart Fail. 2012;14(8):803-69.

2. Askoxylakis V, Thieke C, Pleger ST, Most P, Tanner J, Lindel K, et al. Longterm survival of cancer patients compared to heart failure and stroke: a systematic review. BMC Cancer. 2010;10:105.

3. Alter DA, Ko DT, Tu JV, Stukel TA, Lee DS, Laupacis A, et al. The Average Lifespan of Patients Discharged from Hospital with Heart Failure. J Gen Intern Med. 2012;27(9):1171-9.

4. Maclntyre K, Capewell S, Stewart S, Chalmers JWT, Boyd J, Finlayson A, et al. Evidence of Improving Prognosis in Heart Failure Trends in Case Fatality in 66547 Patients Hospitalized Between 1986 and 1995. Circulation. 2000; 102(10):1126-31

5. Jong $P$, Vowinckel E. Prognosis and determinants of survival in patients newly hospitalized for heart failure: A population-based study. Arch Intern Med. 2002;162(15):1689-94.

6. Formiga F, Chivite D, Solé A, Manito N, Ramon JM, Pujol R. Functional outcomes of elderly patients after the first hospital admission for decompensated heart failure (HF). A prospective study. Arch Gerontol Geriatr. 2006:43(2):175-85.

7. Curtis LH, Greiner MA, Hammill BG, Kramer JM, Whellan DJ, Schulman KA, et al. Early and Long-term Outcomes of Heart Failure in Elderly Persons, 20012005. Arch Intern Med. 2008;168(22):2481.

8. Ezekowitz JA, Bakal JA, Kaul P, Westerhout CM, Armstrong PW. Acute heart failure in the emergency department: Short and long-term outcomes of elderly patients with heart failure. Eur J Heart Fail. 2008;10(3):308-14.
9. Komajda M, Hanon O, Hochadel M, Lopez-Sendon JL, Follath F, Ponikowski $P$, et al. Contemporary management of octogenarians hospitalized for heart failure in Europe: Euro Heart Failure Survey II. Eur Heart J. 2009;30(4):478-86.

10. Barsheshet A, Shotan A, Cohen E, Garty M, Goldenberg I, Sandach A, et al. Predictors of long-term (4-year) mortality in elderly and young patients with acute heart failure. Eur J Heart Fail. 2010;12(8):833-40.

11. Kociol RD, Horton JR, Fonarow GC, Reyes EM, Shaw LK, O'Connor CM, et al. Admission, Discharge, or Change in B-Type Natriuretic Peptide and LongTerm Outcomes Data From Organized Program to Initiate Lifesaving Treatment in Hospitalized Patients With Heart Failure (OPTIMIZE-HF) Linked to Medicare Claims. Circ Heart Fail. 2011:4(5):628-36.

12. Delgado Parada E, Suárez García FM, López Gaona V, Gutiérrez Vara S, Solano Jaurrieta JJ. Mortality and functional evolution at one year after hospital admission due to heart failure (HF) in elderly patients. Arch Gerontol Geriatr. 2012:54(1):261-5.

13. Huynh BC, Rovner A, Rich MW. Long-term Survival in Elderly Patients Hospitalized for Heart Failure: 14-Year Follow-up From a Prospective Randomized Trial. Arch Intern Med. 2006;166(17):1892.

14. Saczynski JS, Darling CE, Spencer FA, Lessard D, Gore JM, Goldberg RJ. Clinical Features, Treatment Practices, and Hospital and Long-Term Outcomes of Older Patients Hospitalized with Decompensated Heart Failure: The Worcester Heart Failure Study. J Am Geriatr Soc. 2009;57(9):1587-94.

15. Scrutinio D, Ammirati E, Guida P, Passantino A, Raimondo R, Guida V, et al The ADHF/NT-proBNP risk score to predict 1-year mortality in hospitalized patients with advanced decompensated heart failure. J Heart Lung Transplant. 2014;33(4):404-11.

16. Cacciatore F, Abete P, Mazzella F, Viati L, Della Morte D, D'Ambrosio D, et al. Frailty predicts long-term mortality in elderly subjects with chronic heart failure. Eur J Clin Invest. 2005;35(12):723-30.

17. VillaCorta H, Mesquita ET, Cardoso R, Bonates T, Maia ER, Silva AC, et al. Emergency department predictors of survival in decompensated heart failure patients. Rev Port Cardiol. 2003;22(4):495-507.

18. Goldberg RJ. Long-term Survival After Heart Failure: A Contemporary Population-Based Perspective. Arch Intern Med. 2007;167(5):490.

19. Hugli O, Braun JE, Kim S, Pelletier AJ, Camargo CA. United States Emergency Department Visits for Acute Decompensated Heart Failure, 1992 to 2001. Am J Cardiol. 2005;96(11):1537-42.

20. Stenholm S, Westerlund $H$, Head J, Hyde M, Kawachi I, Pentti J, et al. Comorbidity and Functional Trajectories From Midlife to Old Age: The Health and Retirement Study. J Gerontol A Biol Sci Med Sci. 2014;24:glu113.

21. Le Corvoisier P, Bastuji-Garin S, Renaud B, Mahé I, Bergmann J-F, Perchet H, et al. Functional status and co-morbidities are associated with in-hospital mortality among older patients with acute decompensated heart failure: a multicentre prospective cohort study. Age Ageing. 2014;12.

22. von Elm E, Altman DG, Egger M, Pocock SJ, Gøtzsche PC, Vandenbroucke JP. The Strengthening the Reporting of Observational Studies in Epidemiology (STROBE) Statement: Guidelines for Reporting Observational Studies. Ann Intern Med. 2007;147(8):573-7.

23. McKee PA, Castelli WP, McNamara PM, Kannel WB. The natural history of congestive heart failure: the Framingham study. N Engl J Med. 1971;285(26): $1441-6$.

24. Rubenstein LZ, Harker JO, Salvà A, Guigoz Y, Vellas B. Screening for Undernutrition in Geriatric Practice Developing the Short-Form MiniNutritional Assessment (MNA-SF). J Gerontol A Biol Sci Med Sci. 2001;56(6): M366-72

25. Kaiser MJ, Bauer JM, Ramsch C, Uter W, Guigoz Y, Cederholm T, et al. Validation of the Mini Nutritional Assessment short-form (MNA-SF): a practical tool for identification of nutritional status. J Nutr Health Aging. 2009:13(9):782-8.

26. Folstein MF, Folstein SE, McHugh PR. "Mini-mental state". A practical method for grading the cognitive state of patients for the clinician. J Psychiatr Res. 1975;12(3):189-98.

27. Derouesne C, Poitreneau J, Hugonot L, Kalafat M, Dubois B, Laurent B. MiniMental State Examination:a useful method for the evaluation of the cognitive status of patients by the clinician. Consensual French version. Presse Med. 1999;28(21):1141-8.

28. Bastuji-Garin S, Joly P, Lemordant P, Sparsa A, Bedane C, Delaporte E, et al Risk Factors for Bullous Pemphigoid in the Elderly: A Prospective CaseControl Study. J Invest Dermatol. 2011;131(3):637-43.

29. D'Ath P, Katona P, Mullan E, Evans S, Katona C. Screening, detection and management of depression in elderly primary care attenders. I: The 
acceptability and performance of the 15 item Geriatric Depression Scale (GDS15) and the development of short versions. Fam Pract. 1994;11(3):260-6.

30. de Craen AJM, Heeren TJ, Gussekloo J. Accuracy of the 15-item geriatric depression scale (GDS-15) in a community sample of the oldest old. Int J Geriatr Psychiatry. 2003;18(1):63-6.

31. Katz S, Ford AB, Moskowitz RW, Jackson BA, Jaffe MW. Studies of illness in the aged. The index of ADL: a standardized measure of biological and psychological function. JAMA J Am Med Assoc. 1963;185:914-9.

32. Podsiadlo D, Richardson $S$. The timed "Up \& Go": a test of basic functional mobility for frail elderly persons. J Am Geriatr Soc. 1991;39(2):142-8

33. Cramér H. Mathematical methods of statistics. Princeton: Princeton University Press; 1946.

34. Spearman C. The Proof and Measurement of Association between Two Things. Am J Psychol. 1904;15(1):72.

35. Akaike H. Information theory and an extension of the maximum likelihood principle. Second Int Symp Inf Theory. 1973;267-81

36. Akaike H. A new look at the statistical model identification. IEEE Trans Autom Control. 1974;19(6):716-23.

37. May S, Hosmer DW. Hosmer and Lemeshow type goodness-of-fit statistics for the Cox proportional hazards model. In: Handbook of statistics 23: advances in survival analysis. Amsterdam: Elsevier B. V.; 2004. pp. 383-94.

38. Royston P, Altman DG. External validation of a Cox prognostic model: principles and methods. BMC Med Res Methodol. 2013;13:33.

39. Chen $\mathrm{CH}$, George SL. The bootstrap and identification of prognostic factors via Cox's proportional hazards regression model. Stat Med. 1985;4(1):39-46.

40. Kiesswetter E, Pohlhausen S, Uhlig K, Diekmann R, Lesser S, Uter W, et al. Prognostic differences of the Mini Nutritional Assessment short form and long form in relation to 1-year functional decline and mortality in community-dwelling older adults receiving home care. J Am Geriatr Soc. 2014;62(3):512-7.

41. Kagansky N, Berner Y, Koren-Morag N, Perelman L, Knobler H, Levy S. Poor nutritional habits are predictors of poor outcome in very old hospitalized patients. Am J Clin Nutr. 2005;82(4):784-91.

42. Pureza V, Florea VG. Mechanisms for cachexia in heart failure. Curr Heart Fail Rep. 2013;10(4):307-14.

43. Fried LP, Tangen CM, Walston J, Newman AB, Hirsch C, Gottdiener J, et al. Frailty in Older Adults Evidence for a Phenotype. J Gerontol A Biol Sci Med Sci. 2001;56(3):M146-57.

44. Rockwood K, Song X, MacKnight C, Bergman H, Hogan DB, McDowell I, et al. A global clinical measure of fitness and frailty in elderly people. CMAJ Can Med Assoc J. 2005;173(5):489-95.

45. McNallan, SM, Chamberlain AM, Gerber Y, Singh M, Kane RL, Weston SA, et al. Measuring frailty in heart failure: a community perspective. Am Heart J. 2013;166(4):768-74.

46. Flynn KE, Piña IL, Whellan DJ, Lin L, Blumenthal JA, Ellis SJ, et al. Effects of Exercise Training on Health Status in Patients With Chronic Heart Failure: Findings From the HF-ACTION Randomized Controlled Trial. JAMA J Am Med Assoc. 2009:301(14):1451-9.

47. Chen YM, Li Y. Safety and efficacy of exercise training in elderly heart failure patients: a systematic review and meta-analysis. Int J Clin Pract. 2013;67(11): 1192-8.

48. Pulignano G, Del Sindaco D, Di Lenarda A, Tarantini L, Cioffi G, Gregori $D$, et al. Usefulness of frailty profile for targeting older heart failure patients in disease management programs: a cost-effectiveness, pilot study. J Cardiovasc Med Hagerstown Md. 2010;11(10):739-47.

49. Zuccalà G, Pedone C, Cesari M, Onder G, Pahor M, Marzetti E, et al. The effects of cognitive impairment on mortality among hospitalized patients with heart failure. Am J Med. 2003;115(2):97-103.

\section{Submit your next manuscript to BioMed Central and we will help you at every step:}

- We accept pre-submission inquiries

- Our selector tool helps you to find the most relevant journal

- We provide round the clock customer support

- Convenient online submission

- Thorough peer review

- Inclusion in PubMed and all major indexing services

- Maximum visibility for your research

Submit your manuscript at www.biomedcentral.com/submit

) Biomed Central 